\title{
What evolutions and technological solutions are necessary for sustainable land transport systems
}

\author{
Bruno Dalla Chiara, ${ }^{1, *}$ \\ ${ }^{1}$ Politecnico di Torino, Dept. DIATI - Transport systems, corso Duca degli Abruzzi 24, 10129 Turin, Italy ${ }^{2}$ EDP Sciences, Production
}

\begin{abstract}
Starting with a glimpse of how mobility and traffic have been evolving in Europe in recent decades, and also with a comparison of motionless communications, the paper considers what mobility and logistics require today, in terms of general trends. In order to try to answer to this question properly, the constraints on transport systems in this first half of the twenty-first century are examined, as far as sustainability is concerned. From such a comprehensive perspective, it is possible to infer solutions for mobility and logistics within urban contexts and for extra-urban transport systems. The conclusions summarise the technological evolutions that can be expected according to the premises, which are therefore compliant with the current and expected environmental constraints and goals.
\end{abstract}

\section{Premise}

The paper is structured as follows:

1. How are mobility and traffic evolving in general?

2. What do mobility and logistics require today, in terms of general trends?

3. What are the constraints - in terms of sustainability (CC) - on transport systems in this first half of the twenty-first century?

4. Expected solutions for transport within urban contexts

5. Expected solutions for extra-urban transport systems

6. The conclusions summarise the technological solutions that can be expected according to the premises, and which are therefore compliant with the present and expected environmental constraints and goals.

\section{How are transport systems, mobility and traffic evolving?}

This section is aimed at briefly describing:

- The main transport and mobility trends during the last century and the beginning of the twenty-first century

- The role of motionless communication

- The daily use of automobiles

The demand for the mobility and transport of goods increased throughout the world during the twentieth century and has continued to do so since the beginning of the twenty-first century, mainly due to the globalisation of production and the rise in economic wealth in consolidating economies. The consequence of this increase in mobility and transport is obviously a rocketing of global fuel consumption, the vast majority of which is currently based on crude oil.
In fact, it is widely known that most transport systems rely on oil-derived fuels, which so far have been concurrently guaranteeing an efficient production, deployment, infrastructural capillarity and user-friendly procurement on a wide scale, which has been reached in nearly half a century. Nevertheless, history is the spectator and creator of recurrent mutations: it appears evident that alternatives to crude oil are currently (approx. 2005-2025/30) being pursued to allow transport systems to move in a sustainable way; a migration that should be managed and accompanied by an evaluation of the past and at the same time favour innovation that can satisfy current needs.

This near-monopoly of crude oil has been reached progressively over a period of about one century in most industrialised countries, matriculating vehicle by vehicle, and has been evolving together with diffused motorisation, with the related competence and scale economies, and as a result it is difficult to eliminate by force in the short-medium term. No other human activities - such as industries and building - are in this extreme situation. Nevertheless, there are solutions available that are oriented towards modern economic, energy and environmental goals within the transport field, solutions that are presently being pursued in Europe and also in Italy [1, 2].

Technological progress - mainly in the so-called green-motor and ITS (Intelligent Transport Systems) fields, in an attempt to reduce dependence on the nearmonopoly of crude oil ${ }^{1}$ and to reduce air emissions - has favoured the development of both new-ICE (Internal Combustion Engines) and electric motors, together with hybrid powertrains for road vehicles, by connecting them

\footnotetext{
${ }^{1}$ For example, nearly $94 \%$ in terms of tons of oil equivalent (toe) in Europe; 93\% in the USA in 2017.
} 
with infrastructures for various aims, including booking facilities for the recharging of batteries. All this has mainly taken place since the beginning of the twentyfirst century in most industrialised countries, but more so in recent years. In the same period, road traffic in the EU and the USA seems to have reached a period of stabilisation, albeit with a slight increase in the last few years (Figure 1).

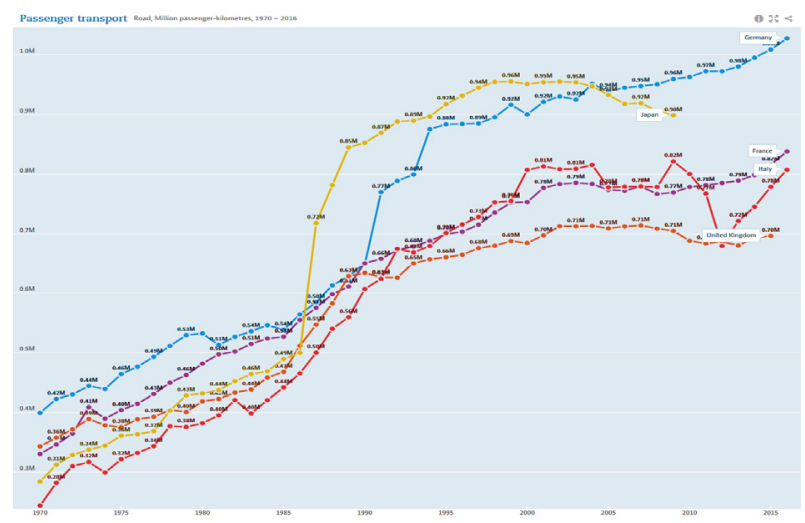

Fig. 1. Millions of passenger kilometres travelled by road, passenger transport, 1970-2015 [3], with focus (top-down) on Germany (light blue), Japan (green), France (purple), Italy (red) and the United Kingdom (orange).

Looking at these trends, it is necessary to outline that, as far as the millions of passenger kilometres travelled by road is concerned, the populations in the countries taken as examples (Germany, Japan, France, Italy and the United Kingdom) are somewhat conservative, but also comparable, and that the demand for mobility is a function of supply. If the supply is not competitive, or there are more interesting alternatives (in terms of actual use of travel time or speed), demand moves elsewhere. Road transport has not only introduced constraints on high speeds in recent years - by adopting enforcement technologies to reduce accidents and to pursue higher safety - but has also suffered from the recent concurrence of high speed trains (HST), which allow passengers to make use of their travel times (work, study, rest, talk, etc.), besides from reducing it with respect to the road alternatives.

The speed of road vehicles and, more recently, of trains (HST) has in fact modified travelling in the last few decades, offering the possibility of both reaching a metropolitan destination, usually in the city centre, in a shorter time than airplanes and automobiles within 600$800 \mathrm{~km}$, and - most of all - of using time in a number of different ways, so that HST has attracted demand.

Another variable also needs to be taken into account in a macro-analysis of the demand for mobility: three decades ago, computers began to modernise almost every aspect of modern human activities. Roughly ten years ago, it was the Internet and, in a broader sense, bidirectional communication that transformed the previously mentioned aspects, as well as the social behaviour of human beings.

The importance of motionless communication in the present historical period thus emerges, this being the great technological revolution of our times in this context [4]. Given the importance that this innovative form of communication has on society, it is logical to presume that it also has an effect on the present concept of motorised mobility, which represented the great revolution of a bygone era. Nevertheless, it is the responsibility and prerogative of the transport engineering field to reinvent motorised mobility in an attractive way in order to guarantee a new cycle, characterised by connected auto vehicles, one day possibly autonomous, automated people movers, diffused ITS and motorised mobility, partially independent of oil derived fuels.

The diagrams in Figure 2 and Figure 3 show the trends of development from 1990 to 2014, and can be studied in order to mathematically analyse what has emerged so far. Figure 2 reports the global growth in the number of Internet users: only the developed world has been considered here. In this case, the trend line that best describes the situation is a simple third-order polynomial equation.

The function that best describes the trend can be identified as

$f=0.0109 x 3-0.6424 x 2+15.644 x-79.522$

with $R^{2}$ (coefficient of determination) $=0.9982$

A point interpolation can be made in order to propose a trend function; in this way, it is possible to see the development that could be expected over the next few years, that is, a further pronounced growth.

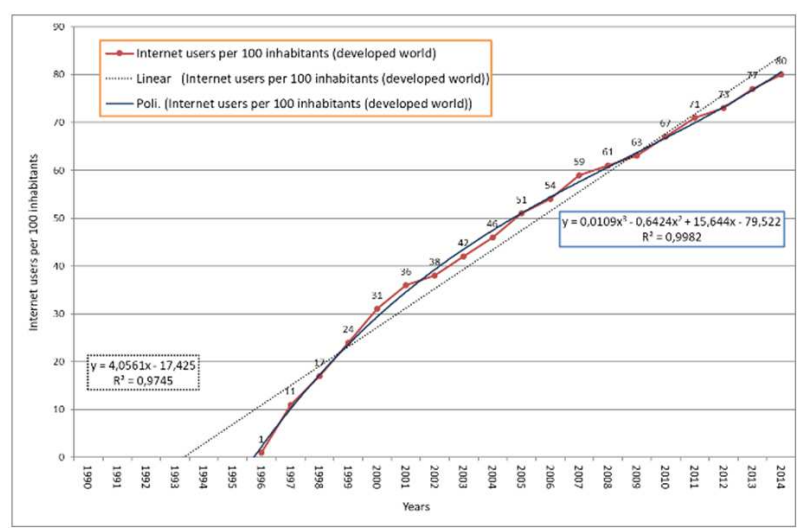

Fig. 2. Internet users per 100 inhabitants [Data source: elaborated on the basis of the International Telecommunications Union]

Figure 3 allows us instead to observe the trend of passenger $\mathrm{km}$ by private cars in two countries: Germany and France. These two countries have been chosen as a representative sample of part of the developed world. The trend functions that best define the situation are logarithmic. 


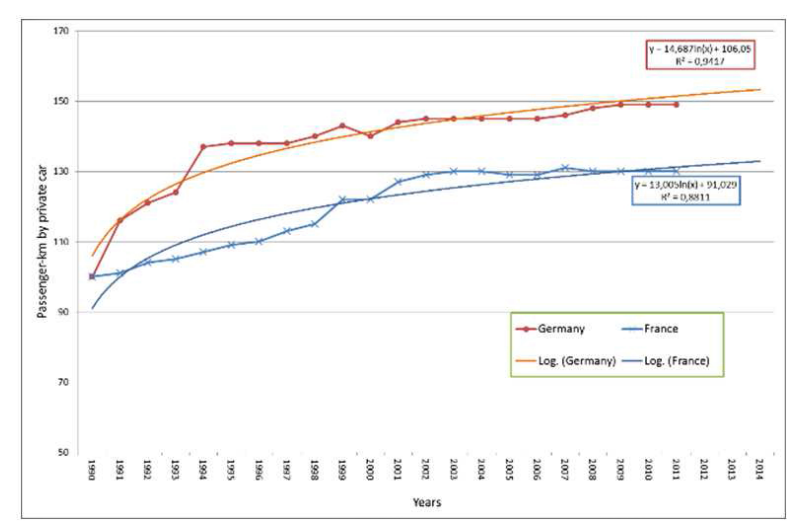

Fig. 3. Passenger $\cdot \mathrm{km}$ by private cars $[$ Year $1990=100]$

Performing the calculation of the first and second derivatives of the functions, in order to study the growth and concavity, it is possible to note that the second derivatives are both negative; in fact, the functions have downward concavity. Furthermore, as a logarithmic function, it can be noted that growth tends to stabilise.

A change in the growth of this type of mobility can be seen, starting from the introduction of the Internet, in favour of motionless communication development; however, motionless communication - through social networks - can also create new links between strangers who decide to meet each other, thereby generating a new demand for mobility. Private motorised mobility needs to be renewed, however, otherwise the current trends of stagnation could continue and could even become worse. Assumptions of static, exogenous consumer preferences can strongly bias the market potential results for new, pro-environmental technologies, in particular with reference to a new concept of connected and green automobiles with assisted driving. Assisted driving requires ICT, creates the bases for automated driving, and inevitably relies on interconnected vehicles. It should be recalled that interconnected here takes the original meaning of intelligent, as it comes from the Latin inter-lego, which means "I link together" or "I link with or through" . This all therefore implies a very wide and long-lasting path for ITS, in this context intended as interconnected and also intelligent transport systems, in which motionless communication is permitted in vehicles so as to continue to allow travellers to have remote connections, even when moving to meet people, for work, actually visiting places physically, practising sport or just for leisure. It is a stimulating but also necessary connection to prevent transport from being partially outranked by motionless ICT uses: ITS can allow a common future of collaboration between transport and communication.

Some authors have not found enough evidence to establish a link between the effects of the contribution of Internet access and the changing of different types of physical activities into virtual activities. In the Netherlands, which is similar to many other countries, a

\footnotetext{
2 Another meaning of inter-lego is "I read through", which means being able to read between the lines, in other words being intelligent.
}

significant change in the use of cars by young adults has been observed, which has decreased since 1995, both in terms of the number of trips and the number of kilometres travelled. However, no clear relationship between changes in driver's licenses and car ownership has been found.

The Internet therefore does not necessarily lead to "motionless mobility", but it may favour the transfer of mobility to other modes of transport: in fact it favours public transport by communicating the waiting times/transition times (thus reducing the generalised cost); or it can favour the efficiency of all the "sharing" enterprises (car, bicycle, motorbike) that are based on a good Internet connection; moreover, the Internet means access to a greater amount of information and this can make users more aware of, and encourage them to make more sustainable choices with respect to the current road mobility proposals (purely polluting).

Nevertheless, a very aggregated analysis of demand trends is not enough to understand the actual daily mobility of people. In order to do so, recent researches have been developed with real data from the automotive field. According to [5] an analysis of a real-life dataset, which refers to an extended period that lasted more than one year, has been conducted pertaining to trips undertaken in Europe by more than 1,000 vehicles and more than 200,000 trips by automobiles. The results are an example of the detailed information that can be extracted from rough data to support the decisions of stakeholders and final users (e.g., car makers, authorities, drivers) in order to understand which road vehicles will be able to comply with the actual daily usage of automobiles in the next few years [6].

The main scope of that analysis was to focus on the variables concerning the duration and lengths of trips, the idle times, and the energy consumed by engines. These variables were correlated and compared with the then and expected hybrid and electric ranges of autonomy, as constrained by the then and next generation of electric batteries, both in terms of autonomy and time required for their recharging. The aim of the study was therefore to find answers to the following research question: considering the daily mileage, actual fuel consumption and idle time structure, could hybrid and electric powertrains represent adequate alternatives to traditional engines, taking into account available battery ranges and charging alternatives?

Long distance trips were analysed in detail to obtain a better understanding of whether they could be covered by electric cars in the same ways as they are with ICE (internal combustion engine)-based ones. In the extensive sample that was analysed, it would be necessary to increase the range to $400 \mathrm{~km} /$ day in order to satisfy $99.9 \%$ of the trips. This target could be reached by adopting a PHEV (plug-in) or a full-electric car with an equivalent range. This study provided a quantitative analysis of the energy needs, obtained over a wide range of usage of road vehicles, and attempted to correlate them with the opportunities for recovering energy during the idle time detected over real-life $24 \mathrm{~h}$ driving cycles, assuming the availability of intermediate charges. 
The driving analysis was conducted by applying two different approaches to the dataset. The first approach was focused on a recorded single trip, and trips were classified individually in relation to their length, duration, idle time and context, considering their frequency of use. This first part was important in order to comprehend the most frequent car usages and identify the structure of representative trips.

The second approach was focused on a more general view, considering all the trips performed each day, in order to provide an overview of the daily usage of the vehicle. This second step was more important for users and car makers, because it showed how different trips comprised the entire daily usage, and provided the daily travelled length and duration with reference to a $24 \mathrm{~h}$ driving cycle.

The frequency of the daily distance for all trips is shown in Figure 4. Extended daily trips are relevant in this context, because, although $99 \%$ of the days per user involves at most $400 \mathrm{~km} /$ day, only $60 \%$ of the days per user involving less than $50 \mathrm{~km} /$ day are observed, whereas this range was observed in $99.9 \%$ of the days for an urban context.

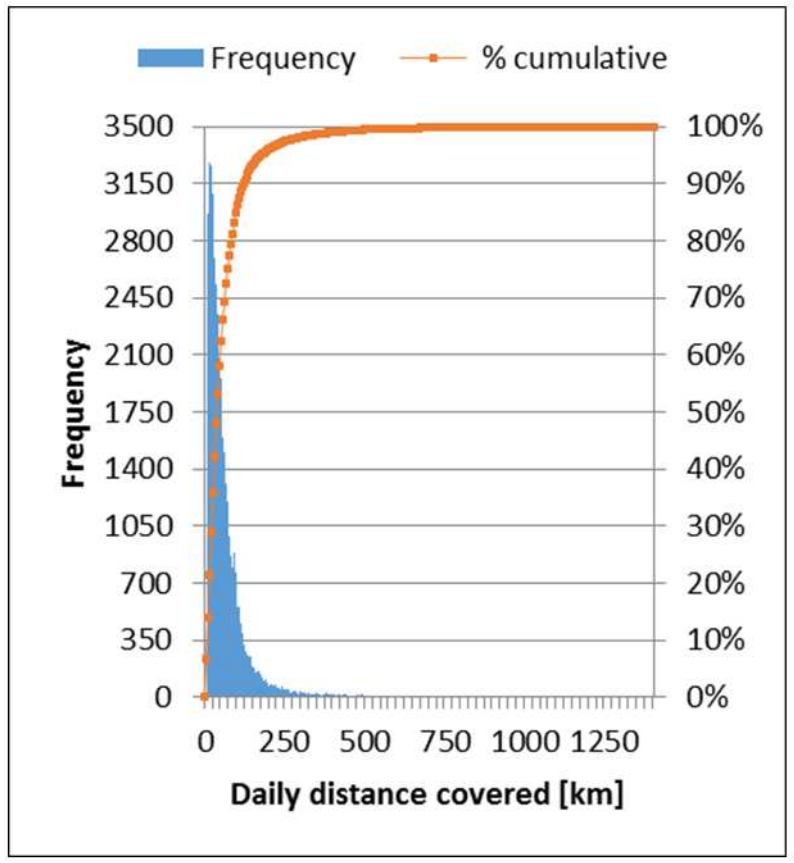

Fig. 4. Frequency [\#days] of the daily distance covered over all the driving cycles (contexts) for all the trips.

The idle time after finishing a journey, which is quite useful in the context of recharging the battery and is compliant with the time requested for such a function, was first depicted for the entire dataset; all the contexts: urban, extra-urban and motorway were included (Figure 5). As can be seen, in approximately $50 \%$ of the cases, the total idle time after finishing a journey is less than 1 hour, $10 \%$ is between 1 to 2 hours, $10 \%$ is between 2 to 4 hours, $10 \%$ is between 4 to 9 hours and it is more than 9 hours for the remaining cases $(20 \%)$.

The results in Figure 6 confirm that approximately $50 \%$ of urban trips present a shorter idle time, after the conclusion of the journey, than 30 minutes. Another $10 \%$ is between 30 minutes and 1 hour, and approximately $20 \%$ falls between 30 and 2.5 hours. In relation to the night-time break, another $10 \%$ of the journeys show a rest time of between 9 and 15 hours.

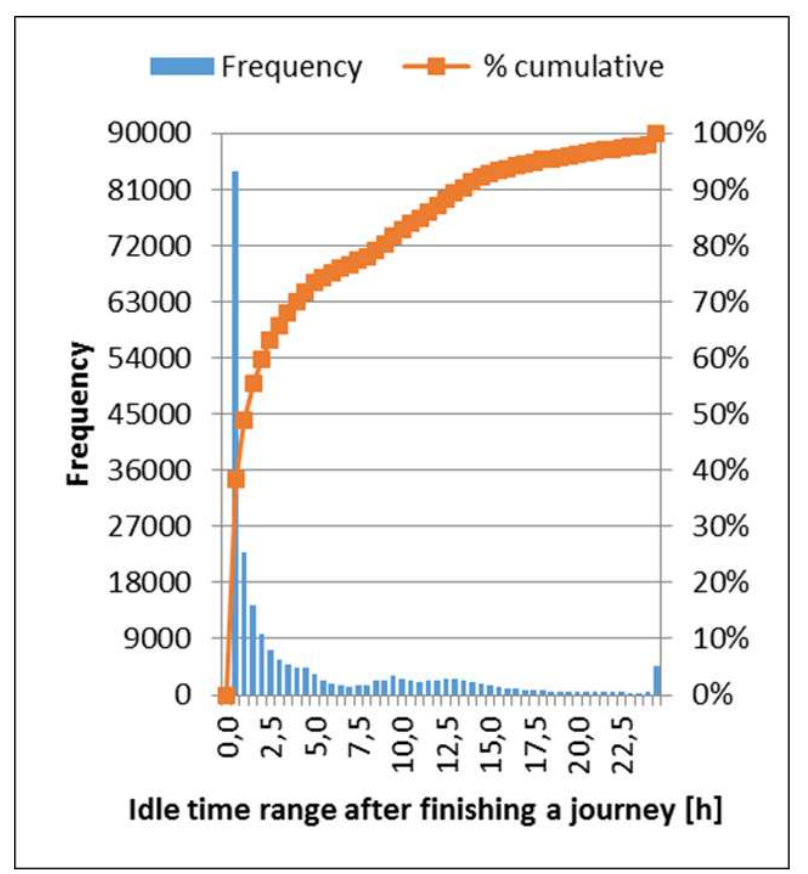

Fig. 5. Idle time after finishing a trip for all the driving cycles.

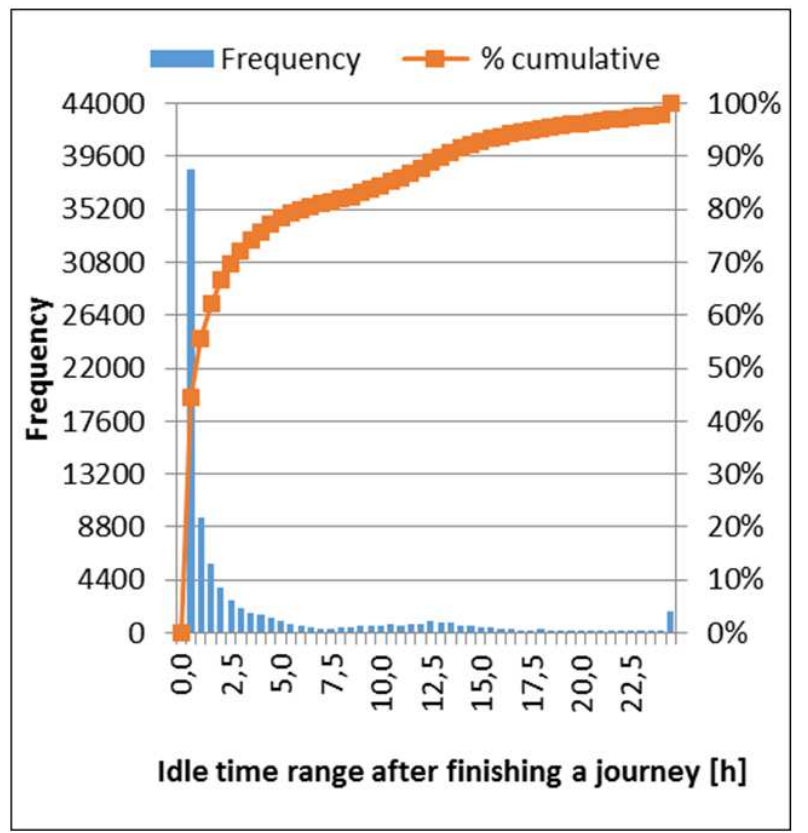

Fig. 6. Idle time after finishing a trip in an urban driving cycle.

\section{What do mobility and logistics require today?}

All the aforementioned general trends and constraints (e.g., the use of oil derived fuels and pollution), associated with the basic concepts of "sustainable transport" - i.e. land use, energy use, environmental 
impact, maintenance, increased safety, level of personal mobility - seem to have had, and will still have in the future, a real impact on the levels of mobility, and therefore require an appropriate analysis for a subsequent general solution, mainly - yet not only - for the transport by land issue.

Furthermore, the industrialised economic system, i.e. that of one of the most mature countries, from the industrial point of view, seems to be passing from a context that is mainly based on both industrial and civil production, the latter being intended specifically as the building of transport infrastructures, to another one based upon maintenance, but also on efficiency, quality and safety.

In order to understand what mobility and logistics require today, we need to depict the situation from an energy and environmental viewpoint, which in the authors' opinion will affect the evolution of transport systems in the next decades to a great extent.

At some points in 2013, transport already accounted for more than $60 \%$ of global oil consumption and more than $27 \%$ of the world's total final energy consumption; it was $\sim 20 \%$ in 2003. In OECD countries, this value (27\%) rises nowadays to more than $30 \%$ (Figure 7 ).

Apart from the direct impact, the production of fuels used in the transport sector also causes indirect emissions.

Focusing on EU-28, about one quarter of the GHG (Greenhouse Gases) emissions from anthropic origin was due to the transport sector until approximatively 5-6 years ago, and now $(2017 / 18)$ they are closer to one third (nearly $30.5 \%$ in 2016 according to the Aspen-Enel documents), mainly as a result of the relatively recent reduction in impact associated with industries, services and buildings. In particular, in $2014,95.1 \%$ of the GHG emissions related to fuel combustion in the transport sector had been generated by road transport, $1.8 \%$ by inland navigation, $1.7 \%$ by inland aviation and $0.1 \%$ by railways; this value $(95.1 \%)$ may be reduced if air transport is considered in a different way, that is, not only including inland aviation, since it can account for approximately $13 \%$ [7].

The carbon dioxide emission rate related to the supply of the whole transport sector does not follow exactly the same slope as the demand for mobility and logistics (transport of goods) [8] since, in spite of having an impact, it is slightly attenuated, thanks to the penetration of naturally electrified means, such as trains, undergrounds, automated people movers (by rope or by rail) in the transport supply, and by improvements in the efficiency of powertrains.

From a policy point of view, according to these premises and the general context, the promotion of the penetration of alternative fuels and energy carriers obviously including electricity - is useful in the transport sector, thus supporting and enhancing the need for new infrastructures: arcs, of the electric grid, and nodes, for recharging or refuelling, whenever useful are among those that may be considered useful.

We need to go into more detail, however, to balance the effects of this migration towards the electrification of the presently un-electrified transport modes, namely road transport, but also - as far as possible - the air, rail and waterway modes.

To achieve sustainability in this sector, most technologically evolved countries have promoted a series of regulations in an attempt to induce a strategic change in the transportation panorama: in the EU, for example, Regulation 397/2013/UE [9] requires a reduction in the average $\mathrm{CO} 2$ emissions, due to the operation of new automobiles, to as low as $95 \mathrm{~g} / \mathrm{km}$ by the end of 2020 . This is surely a challenging target that imposes the introduction of new paradigms and new technologies onto the scene.

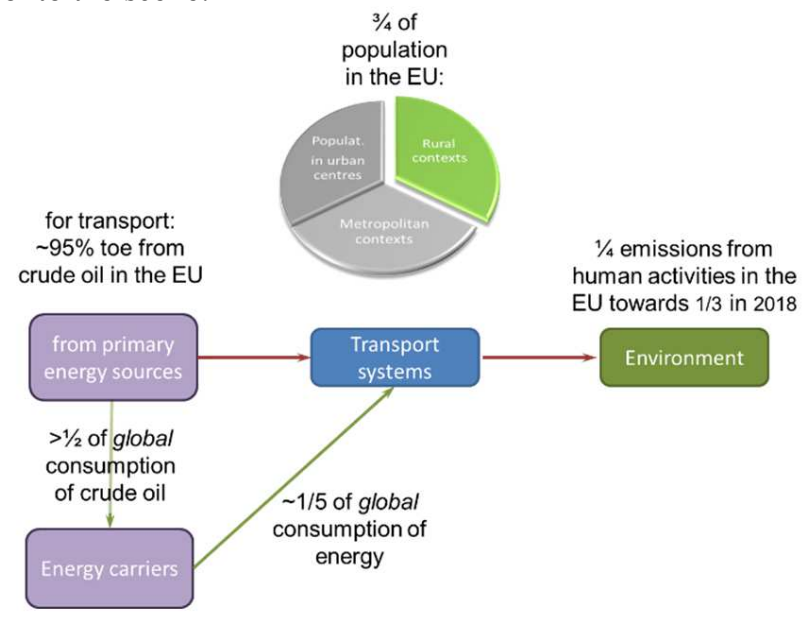

Fig. 7. Relationships of transport systems with their energy usage and impact of the environment

The EU appears determined to tackle the energy issues pertaining to transport sustainability: its White Paper "Roadmap to a Single European Transport Area Towards a competitive and resource efficient transport system" [10] targets ambitious objectives concerning independence from crude oil and the utilisation of technologies in its pursuit, in line with "Horizon 2020". The USA has also taken significant steps (indicatively in 2012-2018) towards independence from crude oil for traction and the propulsion of transport systems. In 2016, Japan declared it was willing to reduce carbon dioxide emissions from transport usage.

In 2011, the White Book on Transport Systems reported a figure of $96 \%$ in the EU, a figure that has reduced to $93-94 \%$ in recent years $(94 \%$ in EU-28 in 2016). These values include capital expenditures: for example, approximatively 67.4 billion Euros (a relevant amount, which is obtained by summing the widely spread small refuelling at petrol stations) - nearly 30 of which is from industrial components - for Italian drivers each year, in 2012-2013-2014: this value was lower in 2014-2015, because of the reduction in cost per barrel of crude oil and of consumption; if the overall amount is reduced by the industrial component, the remaining part is mainly associated with taxes (excises) absorbed by the Government.

According to Eurostat [11], the impact of transport systems in Europe (EU-25) on the overall energy consumption in EU countries resulted to be equal to $30.7 \%$ in 2004; such a value grew to approximately $32 \%$ (2006) and to $33 \%$ (2008) in the following years (EIA, 
2006 and 2008); it was around 33.1\% in EU-28 (28 nations, since 2013) and 34\% in EU-15 in 2015.

The impact of transport systems in Europe is almost $5-10 \%$ greater than the world average (estimated as $20.42 \%$ in 2003 and nearly $27 \%$ in 2013), due to the presence of a larger average motorised mobility than in other continents. Europe shows variability in the impact of transport consumption on the overall final values reported for the different countries.

\begin{tabular}{|c|c|c|c|c|}
\hline Pollutant & Concentration & $\begin{array}{l}\text { Averaging } \\
\text { period }\end{array}$ & Legal nature & $\begin{array}{l}\text { Permitted } \\
\text { exceedances } \\
\text { each year }\end{array}$ \\
\hline $\begin{array}{l}\text { Fine particles } \\
\text { (PM2.5) }\end{array}$ & $25 \mu \mathrm{g} / \mathrm{m}^{3}$ & 1 year & $\begin{array}{l}\text { Target value entered into } \\
\text { force } 1.1 .2010 \\
\text { Limit value entered into } \\
\text { force 1.1.2015 }\end{array}$ & $\mathrm{n} / \mathrm{a}$ \\
\hline \multirow[t]{2}{*}{$\begin{array}{l}\text { Sulphur dioxide } \\
\left(\mathrm{SO}_{2}\right)\end{array}$} & $350 \mu \mathrm{g} / \mathrm{m}^{3}$ & 1 hour & $\begin{array}{l}\text { Limit value entered into } \\
\text { force 1.1.2005 }\end{array}$ & 24 \\
\hline & $125 \mu \mathrm{g} / \mathrm{m}^{3}$ & 24 hours & $\begin{array}{l}\text { Limit value entered into } \\
\text { force 1.1.2005 }\end{array}$ & 3 \\
\hline \multirow[t]{2}{*}{$\begin{array}{l}\text { Nitrogen } \\
\text { dioxide }\left(\mathrm{NO}_{2}\right)\end{array}$} & $200 \mu \mathrm{g} / \mathrm{m}^{3}$ & 1 hour & $\begin{array}{l}\text { Limit value entered into } \\
\text { force 1.1.2010 }\end{array}$ & 18 \\
\hline & $40 \mu \mathrm{g} / \mathrm{m}^{3}$ & 1 year & $\begin{array}{l}\text { Limit value entered into } \\
\text { force 1.1.2010* }\end{array}$ & $n / a$ \\
\hline \multirow[t]{2}{*}{ PM10 } & $50 \mu \mathrm{g} / \mathrm{m}^{3}$ & 24 hours & $\begin{array}{l}\text { Limit value entered into } \\
\text { force 1.1.2005** }\end{array}$ & 35 \\
\hline & $40 \mu \mathrm{g} / \mathrm{m}^{3}$ & 1 year & $\begin{array}{l}\text { Limit value entered into } \\
\text { force 1.1.2005** }\end{array}$ & $\mathrm{n} / \mathrm{a}$ \\
\hline Lead (Pb) & $0,5 \mu \mathrm{g} / \mathrm{m}^{3}$ & 1 year & $\begin{array}{l}\text { Limit value entered into } \\
\text { force } 1.1 .2005 \text { (or } 1.1 .2010 \\
\text { in the immediate vicinity of } \\
\text { specific, notified industrial } \\
\text { sources; a } 1.0 \mu \mathrm{\mu g} / \mathrm{m}^{3} \text { limit } \\
\text { value applied from } 1.1 .2005 \\
\text { to } 31.12 .2009 \text { ) }\end{array}$ & $\mathrm{n} / \mathrm{a}$ \\
\hline $\begin{array}{l}\text { Carbon } \\
\text { monoxide (CO) }\end{array}$ & $10 \mathrm{mg} / \mathrm{m}^{3}$ & $\begin{array}{l}\text { Max. daily } \\
8 \text { hour } \\
\text { mean }\end{array}$ & $\begin{array}{l}\text { Limit value entered into } \\
\text { force 1.1.2005 }\end{array}$ & $n / a$ \\
\hline Benzene & $5 \mu \mathrm{g} / \mathrm{m}^{3}$ & 1 year & $\begin{array}{l}\text { Limit value entered into } \\
\text { force 1.1.2010** }\end{array}$ & $\mathrm{n} / \mathrm{a}$ \\
\hline Ozone & $120 \mu \mathrm{g} / \mathrm{m}^{3}$ & $\begin{array}{l}\text { Max. daily } \\
8 \text { hour } \\
\text { mean }\end{array}$ & $\begin{array}{l}\text { Target value entered into } \\
\text { force 1.1.2010 }\end{array}$ & $\begin{array}{c}25 \text { days } \\
\text { averaged } \\
\text { over } 3 \text { years }\end{array}$ \\
\hline Arsenic (As) & $6 \mathrm{ng} / \mathrm{m}^{3}$ & 1 year & $\begin{array}{l}\text { Target value entered into } \\
\text { force } 31.12 .2012\end{array}$ & $\mathrm{n} / \mathrm{a}$ \\
\hline Cadmium (Cd) & $5 \mathrm{ng} / \mathrm{m}^{3}$ & 1 year & $\begin{array}{l}\text { Target value entered into } \\
\text { force } 31.12 .2012\end{array}$ & $\mathrm{n} / \mathrm{a}$ \\
\hline Nickel (Ni) & $20 \mathrm{ng} / \mathrm{m}^{3}$ & 1 year & $\begin{array}{l}\text { Target value entered into } \\
\text { force } 31.12 .2012\end{array}$ & $\mathrm{n} / \mathrm{a}$ \\
\hline $\begin{array}{l}\text { Polycyclic } \\
\text { Aromatic } \\
\text { Hydrocarbons }\end{array}$ & $\begin{array}{l}1 \mathrm{ng} / \mathrm{m}^{3} \\
\text { (expressed as } \\
\text { concentr. of } \\
\text { Benzo(a)pyrene) }\end{array}$ & 1 year & $\begin{array}{l}\text { Target value entered into } \\
\text { force } 31.12 .2012\end{array}$ & $\mathrm{n} / \mathrm{a}$ \\
\hline
\end{tabular}

Fig. 8. Constraints introduced by Directive 2008/50/EC on ambient air quality and cleaner air for Europe together with the related thresholds

For comparison purposes, it should be noted that the whole transportation system accounted for almost $70 \%$ of crude oil use in the USA from 2008 to 2014 and had an impact of $28 \%$ on the total energy use in the USA [8, 12].

The answer to the question "What do mobility and logistics require today?" can therefore be synthesised in the following four items, which are derived directly from the energy and environmentally related considerations above, and from the previous sections, in particular pertaining to the integration of transport and motionless communication, as well as the profitable use of the time spent travelling:
A. "Green"
(hybridisation,
decarbonisation/ electrification and well-used public transport)
B. Connected vehicles and flexible modal choice
C. Assisted driving
D. Transport systems operating on fixed guideways.

\section{Constraints on transport systems in this first half of the twenty-first century}

It is now necessary to consider the formal constraints recently imposed on transport systems, focussing on the European ones:

- in general;

- on urban pollution;

- on the automotive area.

Let us start with the 2011 edition of the White Book on Transport, and from this, consider the energetic and environmental factors in the transport field.

The "40/27/27" objective was introduced in 2014, at a European level, whereby the EU leaders agreed to pursue a reduction in greenhouse gasses by at least $40 \%$ for renewable energies within 2030, compared to 1990 , and by at least $27 \%$ for energy savings within 2030 , compared to 2014, at a single country level. In 2018, this triad of objectives was increased to 40/32/32.5.

In accordance with Roadmap 2050, concerning energy consumption and greenhouse gas emissions, in order to achieve a policy of competitive and sustainable transport, a part of the White Book is orientated towards the definition of the most ecologically responsible behaviour by citizens in order to achieve good practices that could favour a reduction in greenhouse gas emissions by means of an independence of urban mobility from crude oil. This means the hybridisation of engines (powertrains) and the electrification - but not only - of vehicles, the use of alternative modes to those currently widespread, "conventional", individual motorised transport modes, such as "clean" public transport, soft mobility (e.g., pedestrian and cyclist) and shared services or shared mobility (e.g., car-pooling, carsharing, scooter-sharing, bike-sharing, etc.).

Secondly, the European regulations (Directive 2008/50/EC on "Ambient air quality and cleaner air for Europe") on the quality of air are based on specific principles. The first of these principles foresees that the Member States should divide the territory into zones and agglomerations, for which an evaluation of the levels of air pollution should be made for each, using empirical measurement systems, models or other techniques. Whenever the measured levels exceed the threshold values imposed by the EU, an Air Quality Plan must be drawn up, that is, a programme that has the purpose of guaranteeing the reduction of these values to below such thresholds. Moreover, all the information regarding the quality of air must be communicated to the public organisations in charge.

As far as the emissions generated by transport systems are concerned, it is important to underline the difference between global aspects (analysis scale of carbon dioxide emissions) and local aspects (e.g., changes in the climate at a regional scale, an urban scale, etc.):

1. Global aspects, connected to a Well-to-Wheel analysis. In this context, the local administrative scale does not have much leeway, other than paying attention to the fact that local choices in favour of a reduction of $\mathrm{CO}_{2}$ emissions should be made by 
analysing the overall energy chain at the point in which new energy sources (e.g., electric batteries or hydrogen as a combustible energy vector) are introduced or favoured. Renewable sources play a key role in such an environment;

2. Local aspects, connected to Tank-to-Wheel efficiency: specific interventions, which are more viable at a regional and at a municipality level, are available in this field, although it is necessary to consider:

a. the emissions from transport systems taken as a whole (combustion emissions, but also emissions derived from the wear of brakes and tyres, from the dust raised because of the wear of road surfaces that have not been promptly renewed, etc.);

b. temperature inversion and stack effects in urban environments with respect to the pollution of the surrounding areas;

c. the accumulation of pollutants from motorways, urban rings, roads, etc.;

d. the heating of buildings.

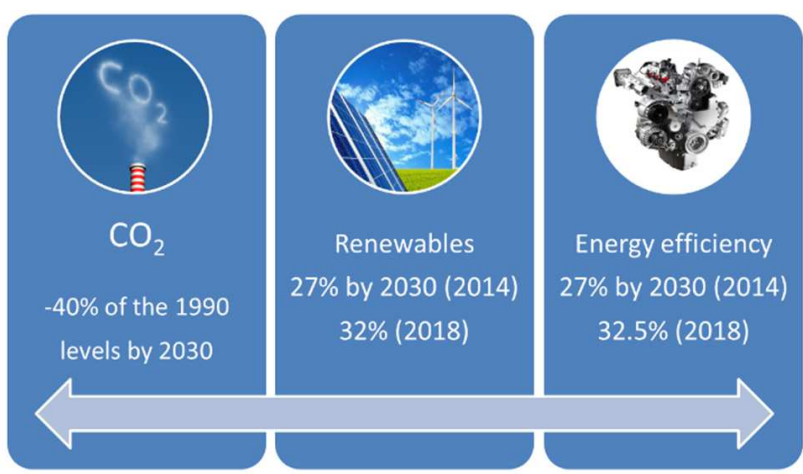

Fig. 9. General aims of the $E U$ in terms of energy and environment

Finally, (the third European constraint), the European Community fixed the levels of performance pertaining to emissions for newly manufactured automobiles and light-duty commercial vehicles in EU Regulation 443 and 510/2009.

Regulation 443/2009 [9] defined the following objectives for new automobiles: a mean limit of 130 $\mathrm{gCO} 2 / \mathrm{km}$, starting from 2015 (the limit was already in force in 2012 and was then progressively extended to higher percentages of automobiles); a further reduction of $10 \mathrm{gCO} 2 / \mathrm{km}$ must still be attained, through the adoption of specific measures relative to the conditioning systems on board, to the monitoring of the pressure of the tyres, to the adoption of low rolling resistance tyres, and to an increase in the use of biofuels; it has also been programmed that the mean level of emissions from automobiles that has to be respected should descend to $95 \mathrm{~g} / \mathrm{km}$ of $\mathrm{CO} 2$ starting from 2020/21. Instead, Regulation 510/2011 fixed the limit to $175 \mathrm{gCO} 2 / \mathrm{km}$ for light-duty commercial vehicles, starting from 2017 , and this should be further reduced to $147 \mathrm{gCO} 2 / \mathrm{km}$, starting from 2020/21.

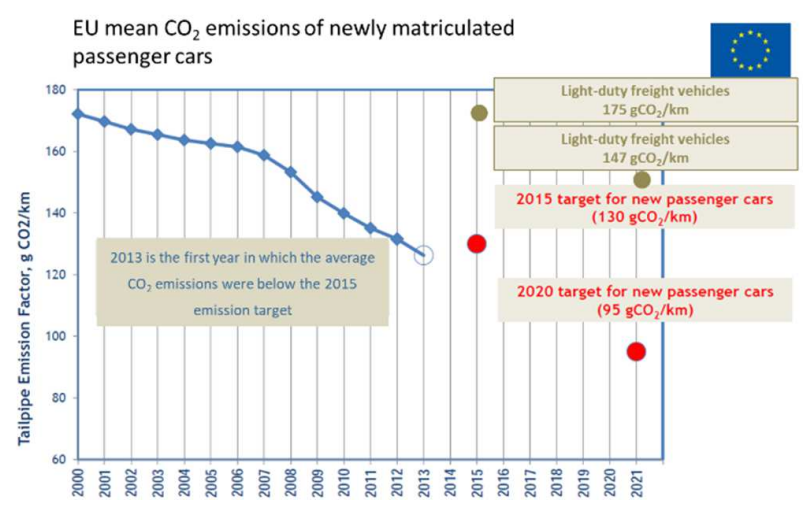

Fig. 10. $\mathrm{CO}_{2}$ emission constraints for automobiles and lightduty road vehicles in Europe [our elaboration from ANFIA, on EEA data]

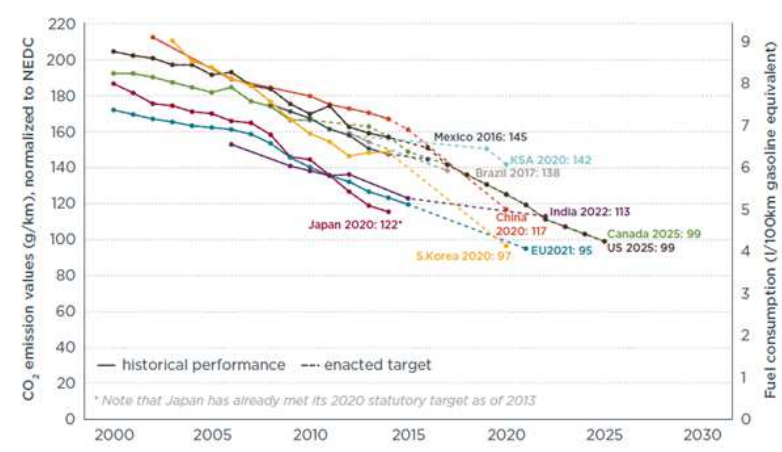

Fig. 11. $\mathrm{CO}_{2}$ emission constraints for automobiles throughout the world: a comparison of regulations

These are limits that should be considered together with the standards, named "Euro", which regulate the emissions of the main pollutants, such as, and in particular, nitric oxides. The "Euro 6" limits (Regulation 715/2007) for automobiles and vans have been applied, starting from 2014, and minibuses and lorries weighing up to 12 tonnes until the end of 2018. The EU has also started to introduce objectives for heavy-duty vehicles: from 2025, the average $\mathrm{CO}_{2}$ emissions from new lorries will have to be $15 \%$ lower than those of 2019. An indicative reduction target of at least $30 \%$, compared to 2019, has been proposed for 2030 .

These targets are consistent with the EU's commitments under the Paris Agreement and will allow transport companies - mostly SMEs - to obtain significant savings, thanks to lower fuel consumption [13].

In order to allow for further $\mathrm{CO}_{2}$ reductions, the Commission is making it easier to design more aerodynamic trucks and is improving the labelling of tyres. It is also putting forward a comprehensive action plan for batteries that will help create a competitive and sustainable battery "ecosystem" in Europe.

All this - alias the pursuit of a greater partial independence from crude oil, "40/27/27" and then " $40 / 32 / 32.5$ ", the reduction of pollutants in urban areas, the respect of the emission limits of cars - means that the accessible and economic integrated/coordinated, multimodality or co-modality mobility may move interest in the use of private cars to alternative means of transport 
and, in part thanks to the spread of vehicles that can use electric traction in urban areas, favour programmes against the negative effects of the present transport systems on urban contexts and on the environment.

Road pricing policies, if correctly planned, can take into consideration effective intervention measures based on direct correlations between external effects on traffic and the vehicle flows that produce them.

\section{Expected transport solutions for urban contexts}

As shown in the first section, most movements in urban environments take place over medium-short distances, and for this reason vehicles with electric traction (not necessarily "pure" electric vehicles) can be a valid alternative to those engines that only have internal combustion, except in the case of longer distances (above, for example, 70-100 kilometres), over which electric vehicles are not able to guarantee the flexibility required of private vehicles for the various possible necessities.

The higher acquisition price and more limited driving autonomy than in vehicles equipped only with internal combustion engines, the greater time required for charging the vehicles, compared to refilling with combustible fuels, and the restricted availability of recharging points outside urban areas are also points that impede the spread of pure electric vehicles.

On the other hand, the refining of battery charging techniques, whether conductive or inductive, helps support the design and spread of hybrid vehicles which, apart from direct recharging (plug-in or contactless), foresee the use of an endothermic engine (often with reduced cylinder capacity or down-sizing and bi/multi fuels) and which, together with an electric battery engine, allows the most suitable type of traction to be chosen for the driving situation and recharging to be conducted independently: thus representing an industrial opportunity.

It is possible to state that, faced with the ongoing technological progress, hybrid and/or pure electric vehicles will become a valid alternative to traditional vehicles over time, on condition that the supply energy comes, in a non-negligible measure, from renewable sources, and that the problem of the disposal or reuse (second life) of the accumulators is addressed and resolved.

These elements are fundamental to a better understanding of where and when it will be possible to affect the transport of people through energetic efficiency and through reductions in emissions in the various modes of ground transport in order to offer the premises of such modes of transport in Europe, even through a future industrial and above all local production.

A role for "green" transport thus emerges, that is, a role that is shared (public transport vehicles falls into this category, as do pure solutions - of much less capacity - such as car sharing), connected and directed towards - for as much as it is useful and possible driving autonomy, in which Turin and Piedmont play a key role. One example of attractive public transport is the automatic underground system in Turin: the Val automatic underground system in Turin accounted for 7 million passengers/year in 2006, in the year of its inauguration, and 41 million in 2015 - a good sign, to say the least.

\section{The expected solutions for extra- urban transport systems}

The new European policies - starting with the White Book of Transport of 2011 - are therefore pushing towards an either total or partial modal transfer (comodality and inter-modality) from road to railway. The railway will thus regain the attention it lost in the past, but on occasion will require technological adaptation, not only for the rolling stock, but also for the infrastructure and the control and signalling systems.

As far as the extra-urban environment is concerned, attention is in fact here focused on railway transport, having already faced the evolution of road vehicles in the previous sections. Railways have little by little lost importance in the transport of goods, compared to road transport, over the last few decades:

- because the transport of the heavy materials - that accompanied the era of large urbanisation, the development of industrial factory plants and motorway infrastructures (1950s to 1980 s) - began to fall,

- but also because there was no renewal of the railway stock directed towards allowing the transport of those goods that require a controlled temperature, such as refrigerated goods and all those products for which a verification of the physical-chemical parameters during movement is required.

This kind of traffic can only be satisfied by particular solutions that resort to carriages with electric generators or insulated crates, but however always with specific solutions and, on occasion, which are only suitable for brief trips in order not to compromise the adiabatic capacity of the insulated or refrigerating crates.

The capacity of the railway sector to attract traffic can today be reached through the use of freight trains possibly with as many as 35 carriages, of a length of 750 $\mathrm{m}$ - with multiple traction, distributed power and single electrified carriages in order to also guarantee the transport of goods at controlled temperatures, and with electric braking commands, always of a pneumatic type, on each single carriage.

The lengthening of trains to $750 \mathrm{~m}$ is a European request that is mainly aimed at a reduction of the unit costs, provided of course that the train is full. This technological leap would therefore also allow trains with 35 carriages to be assembled, with sustained speeds $(120-140 \mathrm{~km} / \mathrm{h})$ and without excessive concentrated power problems - as occurs with traditional locomotives - and presumably incompatible with triple traction, in that the power is distributed along the train, as in the case of the ETR passenger train. The recharging time of a compressed air tank would be much less; the carriages would be individually remotely diagnosable (axles, axle 
boxes and braking systems) in that they could be endowed with sensors connected to an electric communication network on board, a very important requirement since such trains would use high-speed lines. Finally, the goods could be both conservable (for food products and others) and easily monitored, especially for particularly long trips.

As far as the transport of people is concerned, the attractiveness that high speed has generated is unequivocal - although always guaranteeing quality, safety and efficiency of the service. Just a few numbers are sufficient as an example:

a) 240 trains/day - a line that is in fact close to saturation - today on average on the most used stretch of the Lyons-Paris high-speed line, which was inaugurated in 1982 with 7.2 million travellers/year, became 44.4 million in 2017;

b) The Turin-Milan high-speed line, with 7 pairs of weekday trains in December 2009, when it was inaugurated, and with 28 couples for Trenitalia and 21 for NTV in September 2018, and generally with very high occupancy levels.

It is therefore easy to recall that a competitive transport offer is always able to attract the demand and the relative traffic.

Figure 12 shows the maximum speed records which, of course, do not represent the operational speed along the railway lines - that have been reached by trains since the beginning of their history.

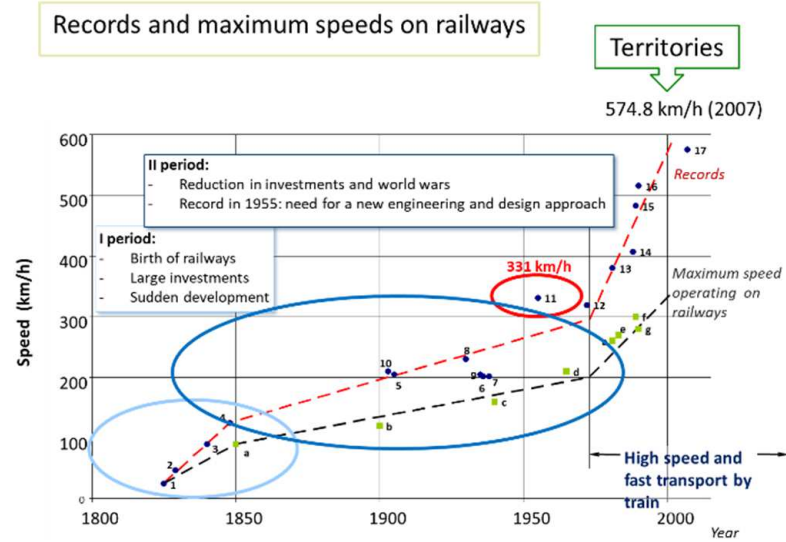

Fig. 12. Records and maximum train speeds

Nowadays, further increases in rail speeds frequently seem to be limited by territories - i.e. the actual distances between cities that can take advantage of the increase in speed - and by the need to select large or important cities when setting up new network branches, thus sometimes betraying or bypassing smaller or medium-sized urban centres. Technical constraints also sometimes play a role, for example, the wear of rails, energy absorption or safety reasons related to train dynamics [14].

\section{Conclusions: technological solutions that can be expected according to the premises, and which are therefore compliant with the present and expected environmental constraints and goals}

Unsurprisingly, the means used to transport people and freight have evolved to a great extent over the last 100 150 years; historical needs and urban development have led humans to first use and exploit animals and then motorised vehicles, in order to significantly increase the speed of movement. Since this speed has increased, it has also been necessary for the space path to increase proportionally to the speed in order to maintain a constant average "travel time budget", which, for the time being, has been considered one hour per day. This concept can be simplified by considering that people generally travel many more kilometres than in the past at higher speeds, but the same amount of time per day is dedicated to moving, for many and varied reasons. For example, rail transport, which has invested a great deal of funds in raising speeds since the 1970s, both by increasing speed itself on existing lines through the introduction of tilting trains and by constructing ad hoc lines for high speed trains, has increased traffic and enlarged its area of influence to $600-800 \mathrm{kms}$, as larger distances are covered at higher speeds, in Japan, France, Germany, Italy, Spain and in other countries [15].

A limit to the increase in the speed of cars - an increase to which the diffusion of highways and motorways led, mainly during the 1960s-1990s - can now be associated with goals of higher safety and, in some cases, with the spread of ITS applications for identifying infringements of speed limits, even in the absence of police forces.

As previously mentioned, the transport sector is mainly characterised by the use of distributed energy vehicles, with the exception, in general terms, of those systems which operate on tracks or fixed installations, such as railways, undergrounds, cableways [16] and automated people movers. In most cases, the energy source is combusted directly in engines on-board vehicles - be they on road, sea, inland waterways or air that are provided with a fuel tank. The shift from such a system to one characterised by partially or totally electrically-powered vehicles, which use electricity generated as much as possible through renewable sources - would produce a strong decarbonisation of the whole transport sector, with several related effects, mainly on the environment and economics, along with some issues that need to be carefully taken into consideration from the social and, to some extent, economic point of view.

We may therefore envisage:

1. A European rail network made up of medium-large size cities in a hierarchical EU co-modal network:

- Mega-cities burn land and depreciate already used land;

- "Stopping" the use of land for construction, while valorising urban heritage; 
- An HSL rail network for medium sized cities;

- Air/train HUBs for very long distances by airplanes.

2. An EU network of rail terminals (inland-portsindustries)

- freight EMUs (electro-motor units), to be introduced;

- HDV (Heavy-duty vehicles) with ICE (Internal Combustion Engine) and PHEV/HEV (Plug-in hybrid electric vehicles/hybrid electric vehicles) for mixed use.

3. Flexible co-modality in cities (the first feasible step against global warming).

4. PHEV (Plug-in hybrid electric automobiles)

- Electric vehicles where the depot or parking is fixed each night;

- Sharing (public transport included);

- MAAS (mobility as a service), when applicable, including micro-mobility (by bicycles, scooters, segways, and the like), when applicable.

\section{References}

1. R. Gerboni, D. Grosso, A. Carpignano and B. Dalla Chiara, Linking energy and transport models to support policy making, Energy Policy, 111, 336-345 (2017).

2. B. Dalla Chiara, Considerations on the demand and use of energy in the transport systems / Considerazioni sulla domanda ed impiego di energia nei sistemi di trasporto, Ingegneria Ferroviaria, LXV (7-8), 673-685 (2010).

3. OECD, Statistics, retrieved (2018).

4. B. Dalla Chiara, L. Cornaglia and F. Deflorio, A macro-analysis of the evolution of motorised mobility and relationships with the development of motionless communication systems, IET Intelligent Transport Systems, 10, 613 - 621 (2016).

5. B. Dalla Chiara, f. Deflorio F., M. Eid, Analysis of real driving data to explore travelling needs in relation to hybrid-electric vehicle solutions, Transport Policy, 80, 97-116 (2019).

6. B. Dalla Chiara and M. Pellicelli, Sustainable road transport from the energy and modern society points of view: Perspectives for the automotive industry and production, Journal of Cleaner Production, 133, 1283-1301 (2016).

7. European Commission, Transport - Statistical Pocketbook (various years).

8. OECD/IEA, Key World Energy Statistics. International Energy Agency, Head of Communication and Information Office, Paris (2015).

9. European Commission, Commission Regulation (EU) No 397/2013 of 30 April 2013 amending Regulation (EC) No 443/2009 of the European Parliament and of the Council as regards the monitoring of $\mathrm{CO}_{2}$ emissions from new passenger cars (2013).
10. European Commission, White Paper Roadmap to a Single European Transport Area - Towards a competitive and resource efficient transport system COM/2011/144, EC (2011).

11. Eurostat, Eurostat Energy Statistical Database (various years) [Online]. Available at: http://ec.europa.eu/eurostat/web/energy/data/databas e [Access date: 10 March 2019].

12. U.S. Department of Energy, Energy Information Administration, Monthly Energy Review (June 2015).

13. European Economic and Social Committee, Opinion of the European Economic and Social Committee on 'The impact of the conclusions of COP21 on European transport policy, Official Journal of the European Union, C 303/02 (19 August 2016).

14. B. Dalla Chiara, R. Ricagno and M. Santarelli, Sostenibilità energetica dei trasporti: analisi dei consumi e della soluzione ferroviaria, Ingegneria Ferroviaria, LXIII (6), 531-543 (2008).

15. B. Dalla Chiara, D. De Franco, N. Coviello and D. Pastrone, Pastrone D., Comparative specific energy consumption between air transport and high-speed rail transport: A practical assessment, Transportation Research Part D: Transport and Environment, 52, Part A, 227-243 (2017).

16. M. Navone, B. Dalla Chiara, S. Blengini and E. Vair, Cable driven Automated People Movers for urban applications: modelling the roller for investigating energy consumption Ingegneria Ferroviaria, LXX, ISSN: 0020-0956. N9, 631-663 (2017). 